\title{
Infraestructura verde, servicios ecosistémicos y sus aportes para enfrentar el cambio climático en ciudades: el caso del corredor ribereño del río Mapocho en Santiago de Chile ${ }^{1}$
}

\author{
Alexis E. Vásquez ${ }^{2}$
}

\begin{abstract}
RESUMEN
El trabajo discute los argumentos a favor de la infraestructura verde urbana y la provisión de servicios ecosistémicos como componentes claves de sistemas urbano-ecológicos resilientes ante al cambio climático. En segundo lugar, se aplica el marco analítico desarrollado al caso del corredor ribereño del río Mapocho en Santiago, discutiendo su aporte actual y potencial para enfrentar el cambio climático a través de la evaluación de tres servicios ecosistémicos claves (1) efecto enfriador, (2) rutas para transporte no motorizado, y (3) mitigación de inundaciones. La integración de los conceptos de infraestructura verde, servicios ecosistémicos y adaptación/mitigación al cambio climático, brinda un marco apropiado para esclarecer cómo los espacios verdes urbanos pueden aportar a enfrentar el calentamiento global y los efectos negativos derivados del cambio climático. En Santiago, el principal aporte del corredor ribereño del río Mapocho es la mitigación de emisiones de gases invernadero al servir como una importante ruta para el desplazamiento no motorizado, especialmente en bicicleta. Su aporte a la disminución de las temperaturas atmosféricas y a la mitigación de inundaciones es mucho más limitado. El desarrollo de un corredor verde ribereño en el río Mapocho puede contribuir a mejorar la provisión de los tres servicios ecosistémicos evaluados y de esta forma constituir importante eslabón en un sistema de infraestructura verde en Santiago para mitigar y adaptarse al cambio climático.
\end{abstract}

Palabras clave: Infraestructura verde, servicios ecosistémicos, mitigación y adaptación al cambio climático.

\begin{abstract}
The paper discusses the arguments in favor of urban green infrastructure and the provision of ecosystem services as key components of urban-ecological systems resilient to climate change. The analytical framework developed here is then applied to the riparian corridor of the Mapocho River in Santiago, in order to discuss its current and potential contributions to tackling climate change. The discussion is based on the evaluation of three key ecosystem services: (1) cooling effects, (2) routes for non-motorized transport, and (3) flood mitigation. The integration of
\end{abstract}

\footnotetext{
1 Investigación financiada por los proyectos FONDECYT Regular $N^{\circ} 1130311$ y No 1130305 . Artículo recibido el 30 de abril de 2014, aceptado el 17 de diciembre de 2014 y corregido el 16 de diciembre de 2015.
}

\footnotetext{
2 Departamento de Geografía, Universidad de Chile (Chile).E-mail: alexvasq@u.uchile.cl
} 
concepts of green infrastructure, ecosystem services and adaptation/mitigation of climate change, provide an appropriate framework to clarify how urban green spaces can contribute to address global warming and the negative effects of climate change. In Santiago, currently the main contribution of Mapocho River's riparian corridor is to mitigate greenhouse gas emissions by acting as an important route for non-motorized transport, particularly for cycling. Currently its contribution to the reduction of atmospheric temperatures and to flood mitigation is limited. The development of a riparian greenway along the Mapocho River could help improve the provision of the three evaluated ecosystem services and thus constitute an important connector in the green infrastructure system in Santiago to address mitigation and adaptation to climate change.

Key words: Green infrastructure, ecosystem services, climate change adaptation and mitigation

El entendimiento de las ciudades como complejos sistemas socioecológicos acoplados pone de manifiesto la imposibilidad de desconocer los procesos ecológicos en la construcción de un proyecto sustentable de ciudad (Pickett et al., 2011; Alberti, 2008).

Los espacios verdes y abiertos urbanos son los lugares donde estos procesos ecológicos encuentran espacio en contextos urbanos (Gill et al., 2007; Haase et al., 2014; Lundy \& Wade, 2011). Sin embargo, aproximaciones clásicas para el estudio, diseño y planificación de los espacios verdes urbanos enfatizan casi exclusivamente los beneficios sociales ligados a la recreación, ocio y belleza escénica dejando fuera todos los muchos otros beneficios ecológicos y sociales que estos proveen (Thompson, 2002; Sukkop y Werner, 1991). Esta perspectiva más clásica de los espacios verdes urbanos está fuertemente ligada a la noción de "jardín", que es conceptualizado como una zona "bien delimitada en la que el hombre manipula y modela la naturaleza para adaptarla a sus propios fines, ya sean estos productivos, estéticos, recreativos o simbólicos" (Santiago-Ramos, 2008: 19). Lo anterior podría ser una de las razones por las cuales, en la práctica, en la planificación urbana se subestime el rol de los espacios verdes en el desarrollo de las ciudades, y por lo tanto tengan una baja prioridad política y en la asignación de presupuestos (CABE Space, 2003; Dunnett et al., 2002, Smaniotto et al., 2008).
Los beneficios sociales y ecológicos de los espacios verdes se vuelven aún más relevantes en contextos de alta incertidumbre como los planteados, por ejemplo, por cambios económicos, sociales y ambientales de carácter global. Dentro de estos últimos destaca el cambio climático, que desafía a las ciudades como principal hábitat de la humanidad a ser activas agentes en la mitigación de la intensidad y velocidad con que se presenta el cambio climático, así como a adaptarse a los impactos adversos derivados del calentamiento global (Hamin \& Gurran, 2009).

Pese a la relevancia de estos temas para la planificación urbana, en la actualidad existe una falta de marcos teórico-metodológicos que vinculen la corriente principal de investigación en servicios ecosistémicos (Ses) con la planificación de espacios verdes urbanos y suburbanos (Hansen \& Pauleit, 2014). Nuevos esfuerzos se deben realizar para desarrollar aproximaciones que vinculen el cuerpo teórico sobre servicios ecosistémicos con la planificación de espacios verdes y abiertos, especialmente aquellas relativas a enfrentar de mejor forma el cambio climático en ciudades.

Este trabajo se plantea como objetivo presentar aproximaciones modernas sobre los espacios verdes urbanos y sus servicios, relacionando los conceptos de infraestructura verde y servicios ecosistémicos para brindar un marco conceptual-analítico adecuado 
para orientar acciones concretas de evaluación, planificación y poner en valor los espacios verdes como estrategia para enfrentar el cambio climático en ambientes urbanos.

\section{Infraestructura verde urbana}

Es imposible pensar en la existencia de una ciudad sin una red de agua potable y alcantarillado, o sin un sistema que colecte y dirija las aguas Iluvia, o sin infraestructura para el tratamiento de aguas residuales domésticas, o sin una red vial interconectada y de gran cobertura. Lo mismo ocurre con aquella infraestructura para la educación o atención de salud.

De manera análoga, en la actualidad es cada vez más difícil concebir el desarrollo de una ciudad sin la planificación y consiguiente inversión e implementación de infraestructura verde (IV) que cumpla algunas de las funciones ya mencionadas $u$ otras diferentes, o mejor aún, que ofrezca al mismo tiempo varias de estas funciones vitales para las ciudades.

Esta perspectiva implica un cambio significativo en la forma en que los gobiernos y las comunidades en general conciben los espacios verdes y su planificación (Benedict \& McMahon, 2000), ya que significa dejar de ver los espacios verdes simplemente como tierras vacantes que aún no han sido urbanizadas (sobre todo aquellas en localizaciones más periféricas) y a la espera de serlo, para verlos como una tipología de uso por sí misma que entrega múltiples beneficios sociales, económicos y ecológicos, y que por lo tanto son un eje estratégico en el desarrollo urbano.

Esta nueva perspectiva se apoya en la definición conceptual de la sustentabilidad como una pirámide, en donde los ecosistemas viables están en la base y sostienen al capital natural, al capital social y al ambiente construido (Williamson, 2003). Bajo esta perspectiva, la infraestructura verde ayudaría a mantener ecosistemas viables y los beneficios asociados al bienestar humano, y en último término a la sustentabilidad ambiental.
Según Benedict y McMahon (2002:5) infraestructura verde puede ser definida como "una red interconectada de espacios verdes que conservan las funciones y valores de los ecosistemas naturales y provee beneficios asociados a la población humana", y aunque esta idea se remonta al 1900 (Benedict \& McMahon, 2006) el término infraestructura verde solamente aparece con fuerza durante la última década en el diseño y planificación de ambientes urbanos y periurbanos (Tzoulas et al., 2007; Eisenman, 2013).

Más allá de esta definición relativamente simple del término infraestructura verde, es posible reconocer el surgimiento de concepciones, métodos y objetos de interés asociados, que definen una aproximación (científico-técnica) que intenta reconciliar crecimiento urbano, bienestar social y protección ambiental, enfatizando los servicios ecológicos y sociales provistos por los espacios verdes en y para las ciudades tales como, regulación climática, purificación del aire, reducción de ruido, refugio de especies nativas, provisión de espacios para recreación, esparcimiento y contacto con la naturaleza.

El campo de la infraestructura verde ha tenido un enfoque eminente práctico, y se ha concentrado en la resolución de problemas tales como los de planificar e implementar estrategias de conservación de sistemas de espacios verdes o parte de ellos. Disciplinas como la planificación ecológica, arquitectura del paisaje y ecología de paisaje han servido como base para el desarrollo de un cuerpo creciente de conocimientos, principios y procedimientos que orientan las tareas ya señaladas. En este sentido, Hansen \& Pauleit (2014) señalan que se necesita vincular cuerpos teórico-conceptuales tales como el de los servicios ecosistémicos, y otros, a la planificación de infraestructura verde, dándole de paso a los primeros una salida aplicada a la planificación urbana.

En la medida que la noción de infraestructura verde ha sido progresivamente aplicada en entornos urbanos, su definición y por lo tanto lo que puede ser o no considerado infraestructura verde se ha ampliado, diversificado y complejizado. En la actualidad podemos encontrar múltiples manifestaciones 
materiales de infraestructura verde, que tienen propósitos específicos muy diferentes y que varían en cuanto al nivel de tecnología incorporado y las escalas que involucradas.

El Cuadro $N^{\circ} 1$ muestra la diversidad de elementos que pueden ser considerados actualmente como infraestructura verde, muchos de ellos ligados a entornos urbanos. Con base en lo propuesto por EEA (2011) y Landscape Institute (2009) a continuación se detallan los elementos de infraestructura verde a las diferentes escalas.

A microescala es posible encontrar techos verdes, jardines verticales y plazas. En un principio el término infraestructura verde estaba centrado en la conservación y mantenimiento de ecosistemas naturales mediante una red de espacios interconectados no incluía este tipo de infraestructura verde.

A escala de paisaje y de región algunos componentes o tipos de infraestructura verde corresponden a humedales, bosques, parques intercomunales, corredores ribereños y líneas de costa. Estos tipos de infraestructura verde son los que permitirían mantener o restaurar procesos ecológicos clave para el funcionamiento a largo plazo de los territorios y maximizar los beneficios sociales que se obtienen de ellos. A estas escalas la infraestructura verde puede ayudar a mantener o restablecer la integridad de paisaje, que corresponde al estado situación donde se hacen compatibles y maximizan la salud de los ecosistemas y el bienestar social (Hellmund \& Smith, 2006).

En ambientes urbanos la necesidad de mantener ecosistemas en buen estado y funcionales que sostengan las actividades humanas es mucho mayor, y no solo en el sentido de actuar como soporte físico de instalaciones e infraestructura sino también como fuente de recursos naturales y como sumidero de energía y materiales; todo lo cual contribuye en último término al bienestar económico, social y sicológico de las personas.

Cuadro $\mathrm{N}^{\circ} 1$

Componentes del paisaje con potencial de infraestructura verde

\begin{tabular}{|c|c|c|}
\hline Escala de barrio & Escala de ciudad & Escala regional \\
\hline Calles arboladas & Ríos y llanuras de inundación & $\begin{array}{l}\text { Áreas Silvestres Protegi- } \\
\text { das }\end{array}$ \\
\hline Techos y paredes verdes & Parques intercomunales & Parques nacionales \\
\hline Plazas de barrio & Canales urbanos & Bordes costeros y playas \\
\hline Jardines privados & Lagunas & $\begin{array}{l}\text { Senderos estratégicos y } \\
\text { de larga distancia }\end{array}$ \\
\hline Espacios abiertos institucio nales & Bosques urbanos & Bosques \\
\hline Estanques y arroyos & Parques naturales & $\begin{array}{l}\text { Fajas de resguardo en } \\
\text { líneas de alta tensión }\end{array}$ \\
\hline Derechos de paso de caminos & Frentes de agua continuos & $\begin{array}{l}\text { Red de carreteras y ferro- } \\
\text { carriles }\end{array}$ \\
\hline Peatonales y ciclo rutas & Plazas municipales & Cinturón verde designado \\
\hline
\end{tabular}


Continuación Cuadro No 1

\begin{tabular}{|c|c|c|}
\hline Escala de barrio & Escala de ciudad & Escala regional \\
\hline Cementerios & Cerros & Tierras agrícolas \\
\hline Pistas deportivas & Grandes espacios recreativos & $\begin{array}{l}\text { Ríos y llanuras de inun- } \\
\text { dación }\end{array}$ \\
\hline Zanjas de inundación & Esteros & Canales \\
\hline Pequeños bosques & Terrenos abandonados & Campo abierto \\
\hline Áreas de juego & Bosques comunitarios & Cordones montañosos \\
\hline Quebradas & Sitios mineros en abandono & $\begin{array}{l}\text { Territorio de propiedad } \\
\text { común }\end{array}$ \\
\hline Patios de la escuela & Tierras agrícolas & $\begin{array}{l}\text { Acueductos y gaseoduc- } \\
\text { tos }\end{array}$ \\
\hline Huertos & Vertederos & Fallas geológicas \\
\hline Terrenos abandonados & & Lagos \\
\hline
\end{tabular}

Fuente: Elaboración propia en base a EEA, 2011 y Landscape Institute, 2009.

Existen varios rasgos interesantes en el concepto de infraestructura verde y la perspectiva que ofrece que hacen interesante su utilización para entender y administrar los espacios verdes urbanos:

1) La inherente responsabilidad social de crear, administrar y mantener IV como elemento clave de la ciudad. Al igual que cualquier otro tipo de infraestructura urbana, la IV o espacios verdes deben ser considerados en la dotación básica del soporte físico para el desarrollo social y económico. Los espacios verdes dejan de ser espacios residuales de los procesos de planificación urbana, para convertirse en parte de sus ejes estratégicos. Esto puede tomar forma como planes maestros de infraestructura urbana.

2) Énfasis en los múltiples SEs más allá de su valor para la recreación y el ocio. El concepto de IV pone en valor los otras múltiples SEs de los espacios verdes que benefician a la sociedad, tales como su contribución al manejo de aguas Iluvia y a mejorar la calidad del aire. La infraestructura verde es esencialmente multifuncional. Consecuente con lo anterior, se abre espacio para considerar una diversidad de espacios verdes diferentes a los parques y plazas tradicionales (ver Cuadro $N^{\circ} 1$ ), y que aportan diferentes beneficios, tie- nen diversos grados de naturalidad y requieren modelos de gestión particulares.

3) Incorporación de dichos SEs en evaluaciones costo-beneficio de proyectos. Desde la perspectiva de la IV es posible valorar económicamente muchos de los SEs ofrecidos por los espacios verdes en las ciudades y con ello incorporarlos en las evaluaciones a las que se someten diversos proyectos urbanos. Lo anterior debería mejorar de manera importante las evaluaciones de proyectos destinados a la conservación, creación y mantención de espacios verdes al interior de la ciudad.

4) Facilidad de entender el concepto por analogía al término infraestructura (gris) clásico. El concepto de infraestructura es amplio y transversalmente usado, es entendido y apropiado socialmente, sobre todo en ambientes urbanos, lo que permite transferirlo con relativa facilidad al ámbito de los espacios verdes y entender su importancia y rol en la construcción de una ciudad funcional y sustentable.

5) Por lo anterior, es posible también extender el principio, y que muchas veces se transforma en una demanda-reclamo, de una buena cobertura y distribución equitativa de la IV. Así como todos los sectores de una ciu- 
dad debería contar con infraestructura sanitaria y eléctrica, de la misma forma no debiesen existir áreas sin cobertura y acceso a IV.

6) Espacios verdes como alternativa a la infraestructura gris para suplir necesidades de primer orden. La IV debiese constituir una alternativa al uso de soluciones altamente tecnológicas e ingenieriles para la resolución de problemas urbanos tales como inundaciones, escasez de agua, disconfort térmico y falta de espacio público. Las soluciones desde la infraestructura gris o ingeniería dura normalmente contribuyen a la solución de uno solo de los problemas antes mencionados debido a su carácter monofuncional, no dan espacio para que ocurran los procesos ecológicos y resultan ser menos beneficiosas en el mediano y largo plazo que la IV.

7) Concepción de los espacios verdes como un sistema espacial y funcionalmente integrado. La infraestructura verde corresponde a un sistema de espacios verdes diversos (tipos de IV) espacialmente en red y funcionalmente complementarios. Este sistema debería permitir el movimiento de fauna, semillas, agua, aire y personas entre los nodos o núcleos por medio de un sistema de escalones (stepping stones) y/o corredores verdes. Es solo al considerar el sistema de infraestructura verde de manera global que cobran importancia propiedades emergentes de este tales como conectividad, equidad y complementariedad.

8) Aumento de la importancia social e institucional de los espacios verdes. Todo lo anterior termina por delinear tal vez uno de los aspectos más relevantes de la perspectiva de los espacios verdes como infraestructura verde, y que se puede resumir en dejar de pensar en los espacios verdes urbanos en algo que, usando las palabras de Walmsley (2006), es "lindo de tener" a algo que "debemos tener".

\section{Servicios ecosistémicos, resiliencia urbano-ecológica e infraestructura verde}

En términos simples los servicios ecosistémicos pueden ser definidos como los beneficios obtenidos por las personas de los ecosistemas (Constanza et al., 1997; MEA, 2005). Estos pueden variar desde los más tangibles como agua potable y alimento, hasta aquellos de carácter sicológico o espiritual, tales como las sensaciones de paz y relajación experimentadas por el contacto con la naturaleza.

Según MEA (2005) los SEs pueden ser clasificados en 4 grandes grupos: soporte, regulación, provisión y culturales (Cuadro $N^{\circ} 2$ ).

Cuadro $\mathrm{N}^{\circ} 2$

Clasificación de servicios ecosistémicos

\begin{tabular}{|c|c|c|}
\hline Servicios de Regulación & Servicios de Provisión & Servicios Culturales \\
\hline Regulación del clima local & Cultivos & $\begin{array}{l}\text { Recreación, turismo y eco- } \\
\text { turismo }\end{array}$ \\
\hline Regulación de la calidad del aire & Forraje & Inspiración y belleza escénica \\
\hline Infiltración y drenaje de aguas & Ganado & Conocimiento de los sistemas \\
\hline Purificación del agua & Fibra & $\begin{array}{l}\text { Experiencia espiritual y reli- } \\
\text { giosa }\end{array}$ \\
\hline Regulación de la erosión & Madera & $\begin{array}{l}\text { Patrimonio y diversidad } \\
\text { cultural }\end{array}$ \\
\hline
\end{tabular}


ENFRENTAR EL CAMBIO CLIMÁTICO EN CIUDADES: EL CASO DEL CORREDOR RIBEREÑO DEL RÍO MAPOCHO EN SANTIAGO DE CHILE

Continuación Cuadro N²

\begin{tabular}{|c|c|c|}
\hline Servicios de Regulación & Servicios de Provisión & Servicios Culturales \\
\hline Protección ante riesgos naturales & Leña & $\begin{array}{l}\text { Patrimonio natural y biodiver- } \\
\text { sidad }\end{array}$ \\
\hline Polinización & Acuicultura & Valor educativo \\
\hline Control de plagas y enfermedades & Alimentos y vegetación & Integración social \\
\hline Descomposición de orgánicos & $\begin{array}{l}\text { Medicamentos y bioquí- } \\
\text { micos }\end{array}$ & $\begin{array}{l}\text { Salud mental y física de per- } \\
\text { sonas }\end{array}$ \\
\hline Reducción del ruido & Agua fresca y potable & \\
\hline Regulación de gaces $\left(+\mathrm{O}_{2}\right.$ y $\left.-\mathrm{CO}_{2}\right)$ & Recursos minerales & \\
\hline Secuestro de carbono & $\begin{array}{l}\text { Recursos energéticos } \\
\text { abióticos }\end{array}$ & \\
\hline Provisión de hábitat & Recursos genéticos & \\
\hline \multicolumn{3}{|c|}{ Formación de suelo, Fotosíntesis, Producción Primaria, Ciclo de Nutrientes, Ciclo del Agua } \\
\hline \multicolumn{3}{|l|}{ Servicios de soporte } \\
\hline
\end{tabular}

Fuente: Elaboración propia en base a MEA (2005), Bolund y Hunhammar (1999), Hernández-Morcillo, Plieninger y Bieling (2013), Kandziora, Burkhard, y Müller (2005 y 2013) y Niemelä et al. (2010).

Aunque la definición y clasificación propuesta por MEA (2005) es la más difundida y utilizada en la actualidad existe un debate respecto a que algunos de los SEs en dicha clasificación deberían ser más bien considerados funciones ecosistémicas, ya que no reportan un beneficio directo a la sociedad. Incluso Fisher et al. (2009) propone diferenciar entre SEs finales e intermedios, siendo los primeros los que están asociados a beneficios sociales directos.

Por ejemplo, la regulación de nutrientes por parte de los ecosistemas es una función que no necesariamente tiene asociado un beneficio directo a la población, incluso la regulación ecosistémica natural podría terminar resultando en una concentración de nutrientes en el suelo dañina para la población. Se puede consultar una discusión bastante elaborada al respecto en Wallace (2007) y Haase et al. (2014).

En el caso de SEs tales como purificación de aire y agua, provisión de agua y alimento, o provisión de espacios para recreación, el beneficio social directo resulta evidente. En este trabajo se utilizarán las consideraciones propuestas por Boyd y Banzhaf (2007) y WaIlace (2007) discutidas anteriormente, declinando utilizar aquellos SEs o denominaciones que pudiesen corresponder a funciones ecosistémicas.

El desarrollo de las ciudades ha involucrado naturalmente la pérdida de ecosistemas por acciones humanas directas, tales como, reemplazo de humedales, bosques, praderas y zonas ribereñas por edificaciones, y también indirectas derivadas de la actividad humana, como explotación de recursos naturales y contaminación ambiental. La pérdida de ecosistemas y la alteración de su estado y funcionamiento producen necesariamente también una disminución y pérdida en la provisión de SEs en un determinado territorio.

La desaparición de ecosistemas y el reemplazo de superficies vegetadas por edificaciones y otras superficies impermeables como estacionamientos, techos y calles suponen un territorio una pérdida global de su capacidad para, por ejemplo, (1) purificar el aire por medio de la fijación de carbono, la reten- 
ción de material particulado atmosférico y la producción de oxígeno, (2) servir de hábitat a especies de vida silvestre, (3) controlar el exceso de escurrimiento y los consecuentes problemas de erosión e inundaciones, (4) moderar las temperaturas del aire por medio de la evapotranspiración y sombreamiento asociado a la vegetación, y (5) la capacidad para mantener ciclos ecológicos. Todo lo anterior afecta la posibilidad de mantener ecosistemas urbanos autosostenidos que no requieran subsidios energéticos ni materiales.

A la par con la disminución de la capacidad de los ecosistemas de proveer SEs en ambientes urbanos y periurbanos, existe un aumento en la necesidad y demanda por dichas funciones (CBO, 2013; Lauf et al., 2014). El aumento en la densidad poblacional y de actividades productivas supone, primero, un aumento en la demanda por los recursos naturales de los ecosistemas para el consumo directo por parte de la población o su incorporación como insumos en los procesos de transformación industrial, segundo, un aumento en la demanda sobre los espacios abiertos y verdes para actividades recreativas, ocio y contacto con la naturaleza, y tercero, una mayor necesidad de la capacidad depuradora de los ecosistemas para el tratamiento de residuos sólidos, líquidos y atmosféricos.

En síntesis el desarrollo de las ciudades ha dado origen a una paradoja en donde, por un lado existe una desaparición y fragmentación de ecosistemas que produce una disminución en la provisión de SEs vitales para la población, y por otro hay un aumento de la demanda social (en un sentido amplio) de estos SEs.

La magnitud de la brecha entre provisión de SEs y demanda por ellos podría ser un buen indicador del funcionamiento y estado de lo que según la Resilience Alliance (2007) corresponde a dos de las cuatro dimensiones para el estudio de la resiliencia urbana: Ambiente Construido y Flujos Metabólicos. La relación entre la medida en que los ecosistemas son capaces de proveer bienes y servicios a la población así como de depurar sus residuos, y la intensidad de la demanda social existente por estos servicios y productos define muy importantemente la manera en que las ciudades pueden enfrentar el cambio de buena manera, y por lo tanto que tan resilientes son.

\section{Infraestructura verde como estrategia para enfrentar el cambio climático en ciudades}

En términos generales, la infraestructura verde puede ayudar a enfrentar el cambio climático de dos formas, primero, aumentando los niveles globales de resiliencia del sistema urbano-ecológico y con ello mejorar su preparación para escenarios de alta incertidumbre, y segundo, a través de la provisión de SEs que permitan enfrentar aspectos específicos relacionados con el cambio climático (Gill et al., 2007).

Es esta segunda aproximación la que se prefiere y desarrolla en este trabajo debido a la mayor posibilidad de operacionalización y de ser evaluada empíricamente.

En este sentido, en la literatura es posible encontrar que de los muchos SEs ofrecidos por la infraestructura verde son solo algunos los que se reconocen como más relevantes para enfrentar el cambio climático en las ciudades. Además, estos son normalmente clasificados de acuerdo a si actúan como mecanismos de mitigación o adaptación al cambio climático (Cuadro $N^{\circ} 3$ ). 
Cuadro $\mathrm{N}^{\circ} 3$

Servicios ecosistémicos importantes para enfrentar el cambio climático

\begin{tabular}{|l|l|}
\hline \multicolumn{1}{|c|}{ Mitigación } & \multicolumn{1}{c|}{ Adaptación } \\
\hline -Secuestro de carbono. & -Mitigación del efecto de isla de calor urbana. \\
-Promoción de viajes sustentables. & -Almacenamiento de agua en el subsuelo, \\
-Reducción del uso de energía para calefac- & disminución del escurrimiento superficial y del \\
ción y enfriamiento. & riesgo de inundación. \\
-Provisión de energía renovable. & -Reducción de erosión del suelo. \\
-Provisión de materiales de construcción me- & -Fortalecimiento de la resiliencia de los ecosis- \\
nos intensivos en energía. & temas al cambio climático. \\
-Producción de alimentos próximos a destinos & -Control de desbordes de ríos y marejadas en \\
de consumo. & zonas costeras. \\
\hline
\end{tabular}

Fuente: Elaboración propia en base a EEA (2011); Kazmierczak \& Carter (2010); NCCAP (2010).

La mitigación al cambio climático ha estado asociada principalmente a los esfuerzos por disminuir la emisión actual y futura de gases invernadero que afectan directamente la intensidad y velocidad a la que aumenta y aumentará la temperatura global (Hamin \& Gurran, 2009; IPCC, 2007). Por otra parte, la adaptación al cambio climático se refiere a todas aquellas acciones destinadas a reducir la vulnerabilidad frente a peligros y daños derivados de nuevas condiciones climáticas (Feenstra et al., 1998).

Según el IPCC (2007) mitigación y adaptación al cambio climático deben ser tratadas como aproximaciones complementarias e indivisibles a la hora de intentar evitar todos los impactos del cambio climático. La adaptación es vital para enfrentar los impactos del calentamiento global pero si no existieran mitigaciones para aminorar el cambio climático, las condiciones resultantes podrían sobrepasar la capacidad de los sistemas naturales y humanos para adaptarse.

Pese a lo anterior, los esfuerzos puestos hasta el momento sobre la mitigación han sido mucho más significativos que aquellos destinados a la adaptación, por lo que la adaptación al cambio climático emerge actualmente como uno de los temas más relevantes para los países y ciudades al enfrentar el cambio climático (Hamin \& Gurran, 2009).
Una de las grandes ventajas u oportunidades que entrega la implementación de IV, es que utilizando diseños adecuados esta puede contribuir de manera simultánea tanto a mitigar el cambio climático como a adaptarse a los efectos derivados de él. En este sentido, la utilización de IV para enfrentar el cambio climático y sus efectos, presenta ventajas por sobre otras estrategias derivadas de su carácter multifuncional o multipropósito.

En el Cuadro $\mathrm{N}^{\circ} 3$ se muestran los SEs que ayudan a mitigar el cambio climático. En este sentido, aparece como importante la capacidad de los ecosistemas para almacenar y secuestrar carbono, y con ello reducir el $\mathrm{CO}_{2}$ atmosférico que es uno de los principales gases invernadero precursores del calentamiento global. En el mismo sentido, son importantes las posibilidades que ofrecen los espacios verdes tales como parques y corredores verdes como rutas de transporte no motorizado (pedestre y de bicicletas) y con ello desincentivar el uso del automóvil y disminuir la emisión de gases invernadero. Otro aspecto relevante es la capacidad de los ecosistemas de regular la temperatura, lo que puede reducir considerablemente la energía usada para enfriamiento en verano y calefacción en invierno. Por último, los ecosistemas proveen fuentes para el desarrollo de energías alternativas tales como energía eólica, hidroeléctrica y bioenergía. 
Por otra parte están los SEs que favorecen la adaptación al cambio climático y moderan sus impactos negativos potenciales. Además de producir una disminución del consumo energético, el efecto moderador de las temperaturas del aire que tienen los espacios verdes contribuye a disminuir los efectos negativos del efecto de Isla de Calor Urbana (ICU) tales como estrés térmico y disconfort de la población. La capacidad de los ecosistemas de regular el ciclo del agua implica un mayor almacenamiento de agua en el suelo y subsuelo, y consecuentemente una disminución del escurrimiento superficial y por lo tanto también de los problemas derivados de inundaciones. Asociado a lo anterior, los espacios verdes en las ciudades son de los pocos espacios donde el agua proveniente de las precipitaciones puede infiltrar y almacenarse en las napas subterráneas y quedar disponible para su uso en épocas de déficit hídrico. Finalmente, la infraestructura verde es especialmente importante en la adaptación de las especies de fauna silvestre a las nuevas condiciones climáticas al configurar matrices urbanas viables en términos de hábitat y más permeables al movimiento.

\section{El caso del corredor ribereño del río Mapocho en Santiago de Chile}

Santiago de Chile se sitúa en una cuenca hidrográfica bastante cerrada, rodeada por el este por la cordillera de los Andes con altitudes cercanas a los $5.000 \mathrm{~m}$ de altitud y por oeste por la cordillera de la Costa de altitudes menores. Desde los Andes el río Mapocho y un conjunto de quebradas transportan agua $y$ sedimento, casi siempre torrencialmente, hasta el océano Pacífico localizado a solo 250 kilómetros de distancia.

Un clima de características mediterráneas con una estación seca prolongada domina la ciudad, siendo julio el mes más frío y enero el más cálido con temperaturas promedio de 7,7 y $21,2{ }^{\circ} \mathrm{C}$ respectivamente. En Santiago el promedio anual de lluvias es de $350 \mathrm{~mm}$ y se concentran entre mayo y agosto (meses de invierno). Las condiciones semiáridas son una de las características más importantes en térmicos climáticos.
La gran variabilidad interanual es otra característica climática relevante. Durante los años El Niño, la lluvia puede alcanzar 800 $\mathrm{mm}$, pero cuando la Niña ocurre, las Iluvias pueden descender a cerca de 100 mm (Romero, 1985).

Ahora bien, según las proyecciones climáticas realizadas por el Departamento de Geofísica de la Universidad de Chile (2006) para la Región Metropolitana de Santiago, considerando escenarios moderados y severos de cambio climático, en el futuro las temperaturas mínimas y máximas aumentarán y las precipitaciones anuales disminuirán. Rasgos importantes de estas variaciones climáticas para el bienestar social y urbano son la probabilidad de encontrar en el futuro más días anuales que sobrepasen temperaturas de $30^{\circ} \mathrm{C}$ y episodios de lluvias más intensos (CAS, GORE, MMA y SEREMI MMA, 2012).

Por otra parte, Santiago es la séptima ciudad más poblada de América Latina con casi ocho millones de habitantes y es por mucho la ciudad más importante de Chile, ya que concentra el $42,7 \%$ del PIB (en 2006, INE 2009) y el $40,3 \%$ (en 2009, INE 2009) de la población a nivel nacional. Santiago ha triplicado su tamaño en los últimos treinta años debido a una expansión acelerada que ha significado la sustitución de tierras agrícolas, bosque y matorral nativo y la ocupación de antiguos cauces de ríos y quebradas (Romero et al., 2012).

Esta dinámica urbana se ha caracterizado por originar una ciudad en constante colisión con las características y flujos (de materia y energía) propios de los sistemas naturales asociados a las condiciones geográficas dominantes. Esta desarticulación estructural se manifiesta en numerosos problemas ambientales, entre los cuales se cuentan el aumento en las temperaturas superficiales y atmosféricas de la ciudad (Molina, 2007), la desaparición acelerada de las superficies vegetadas (Vásquez y Romero, 2007), una importante interrupción de los flujos de vientos (Romero y Vásquez, 2006), sedimentos y aguas, y finalmente, una exposición cada vez mayor de la población a riesgos ambientales.

Todos los problemas anteriormente mencionados ponen en tela de juicio la sustenta- 
bilidad ambiental a largo plazo de Santiago y señalan la urgente necesidad de restablecer y mejorar la articulación entre el sistema natural y el sistema social-urbano. Lo anterior pasa necesariamente por reconocer y valorar adecuadamente los espacios abiertos y verdes que prestan valiosos servicios ecosistémicos en entornos urbanos (Girling et al., 2000, Gill et al., 2007).

Algunos de los espacios verdes que requieren especial atención para su conservación y como base para el desarrollo de infraestructura verde son los humedales urbanos, ríos, quebradas, bosques y corredores ribereños, ya que son componentes estructurales en paisajes urbanos y conexiones críticas para procesos ecológicos que se desarrollan en las ciudades. Girling et al. (2000) denomina a estos espacios verdes clave Bienes Ambientales o Activos Ambientales.

Un adecuado reconocimiento, valoración y consideración de estos bienes ambientales en la planificación urbana, asignación de usos de suelo y diseño urbano pueden ayudar a asegurar la integridad del ecosistema urbano, y por esta razón, aumentar la resiliencia urbana y la capacidad de las ciudades para enfrentar el cambio climático (Girling et al., 2000; Jackson, 2003).

Los corredores ribereños a lo largo de cursos de agua pueden proveer múltiples SEs tales como mejorar la calidad de curso de agua principal, controlar la erosión lateral y crecidas, proveer hábitat para fauna silvestre, regulación microclimática, reducir los niveles de ruido y la temperatura del agua, y por último, facilitar la infiltración de agua en el suelo (Schreier et al., 2004; Maekawa \& Nakagoshi, 1997; Apan et al., 2002).

Los corredores verdes son comúnmente definidos como áreas verdes lineales con múltiples funciones sociales y ecológicas. Su desarrollo ha estado históricamente asociado muy de cerca a las zonas y corredores ribereños. Zonas ribereñas bien preservadas pueden actuar como efectivos corredores verdes, proveyendo valiosos SEs como los mencionados anteriormente más aquellos de tipo cultural, incluyendo sitios para transporte no motorizado (caminar, correr y andar en bicicleta), oportunidades para recreación y ocio, conservación de herencia cultural, y calidad estética (Hellmund y Smith, 2006).

En la segunda parte de este trabajo se usa el caso de la zona ribereña del río Mapocho en Santiago de Chile para explorar y discutir el aporte actual y potencial de la infraestructura verde a la mitigación y adaptación al cambio climático en ciudades. Lo anterior basado fundamentalmente en la evaluación concreta de tres servicios ecosistémicos (1) efecto enfriador, (2) rutas para transporte no motorizado, y (3) mitigación de inundaciones.

\section{Metodología}

Según Vásquez et al. (2010) las franjas ribereñas urbanas en Santiago no han logrado escapar del proceso de urbanización y es frecuente encontrarlas ocupadas por sectores residenciales. En el caso de la zona ribereña urbana del Mapocho, ellos describen que si bien es cierto existe algo más de un $30 \%$ de superficie ocupada por sectores residenciales, industrias y autopistas urbanas, aún existen proporciones similares de espacios verdes y abiertos a lo largo del corredor ribereño, que por tramos alcanzan altos niveles de conectividad espacial.

Para este estudio se define operativamente el área bajo análisis como un buffer de 200 $\mathrm{m}$ entorno al río Mapocho en su tramo urbano, más $2.000 \mathrm{~m}$ antes de ingresar al área construida y $2.000 \mathrm{~m}$ aguas abajo después de abandonar la ciudad (Figura $N^{\circ} 1$ ).

\section{Selección de servicios ecosistémicos a evaluar}

En primer lugar, en base a una revisión de literatura se elaboró una lista de 15 SEs que podrían proveer los corredores ribereños en áreas urbanas.

Esta lista fue presentada y discutida con un panel de 21 expertos y actores locales provenientes de ministerios, municipalidades, universidades, empresas y ONGs, con el objeto de seleccionar aquellos servicios ecosistémicos que les parecieran más relevantes 
y necesarios en el caso de Santiago. El taller se realizó el 26 de enero del año 2011 y tuvo una duración de 2 horas.

Este proceso redujo la lista inicial de 15 a 7 SEs. Estos 7 SEs fueron ranqueados por 33 actores de instituciones públicas pertinentes en el tema de las áreas verdes urbanas y zonas ribereñas. Esto se realizó mediante un cuestionario en línea y las personas fueron seleccionadas siguiendo un muestreo de bola de nieve (Goodman, 1961).

$\mathrm{Ni}$ en el taller ni el cuestionario se les preguntó directamente por servicios ecosistémicos importantes para enfrentar el cambio climático, sino por aquellos que ellos juzgaran como más necesarios en Santiago de Chile.

Figura $\mathrm{N}^{0} 1$

Localización del área de estudio en la ribera del río Mapocho
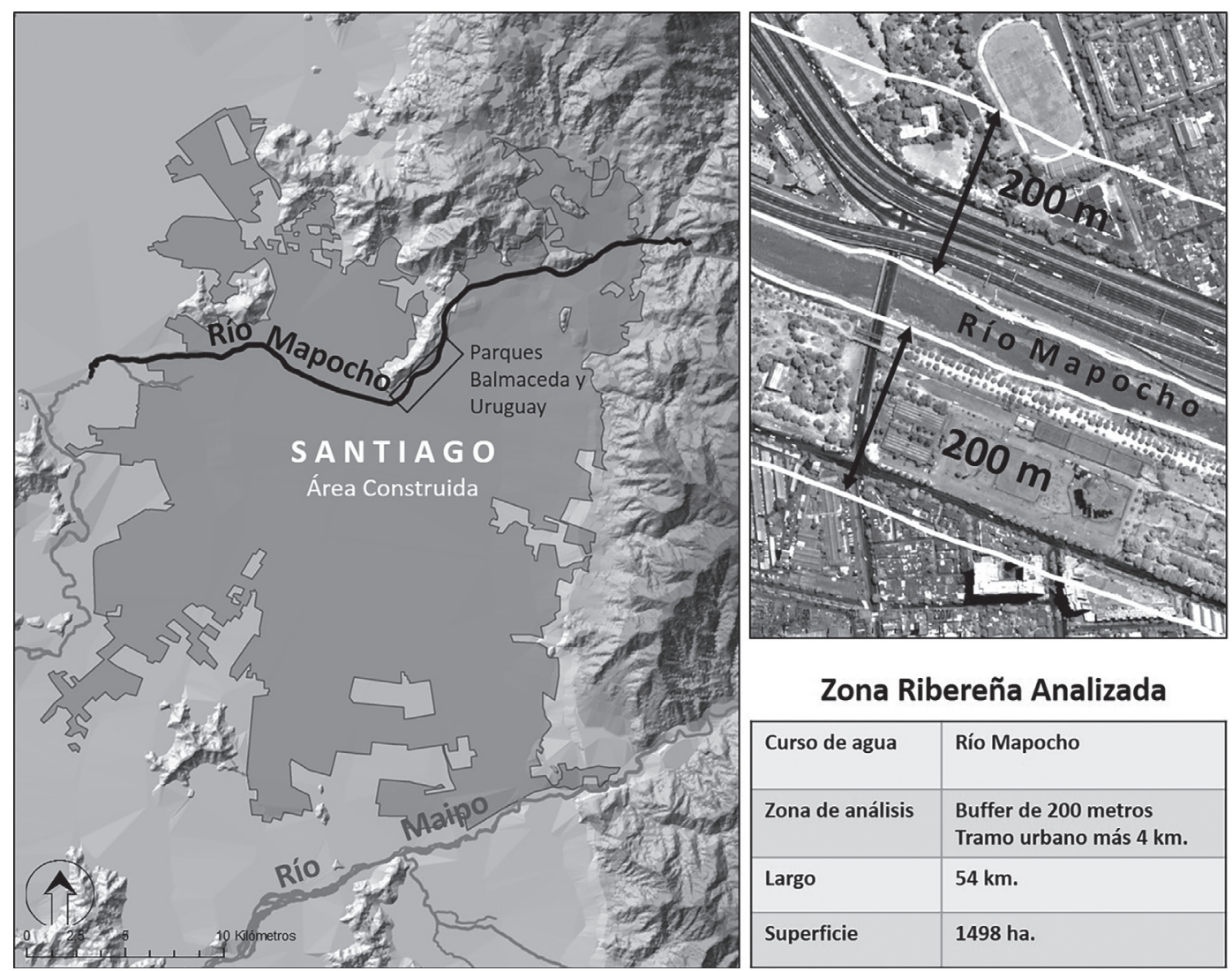

Zona Ribereña Analizada

\begin{tabular}{|l|l|}
\hline Curso de agua & Río Mapocho \\
\hline Zona de análisis & $\begin{array}{l}\text { Buffer de } 200 \text { metros } \\
\text { Tramo urbano más } 4 \mathrm{~km} .\end{array}$ \\
\hline Largo & $54 \mathrm{~km}$. \\
\hline Superficie & 1498 ha. \\
\hline
\end{tabular}

Fuente: Elaboración propia.

En el último paso de esta etapa se seleccionaron 3 SEs relacionados con mitigación y adaptación al cambio climático para ser analizados posteriormente en detalle: 1) efecto enfriador, (2) rutas para transporte no motorizado, y (3) mitigación de inundaciones.
Se descartó evaluar la función del corredor ribereño como corredor de viento debido a la imposibilidad de contar con registros de larga data y resolución espacio-temporal adecuada. 


\section{Efecto enfriador}

Para reconocer los patrones termales de las zonas ribereñas se realizaron tanto transectos móviles como la instalación de registradores estacionarios de temperatura. Los transectos móviles siguieron perfiles transversales con respecto al cauce principal y se emplearon estaciones meteorológicas móviles debidamente calibradas para realizar mediciones en invierno y verano en tres horarios (mañana, mediodía y noche). Los perfiles transversales se distribuyeron a lo largo del curso de agua de acuerdo los usos/coberturas dominantes y a la disponibilidad de puentes o lugares que permitieran cruzar fácilmente el cauce. Esto dio origen a 14 transectos. Las campañas de terreno involucraron dos días de mediciones en invierno y dos días en verano del año 2011.

El uso de los registradores de temperatura tuvo por objeto tener registros con una mejor resolución temporal y durante un periodo de tiempo mayor. Registradores de Temperatura HOBO fueron instalados en tres parques ribereños de las secciones oriente, centro y poniente siguiendo perfiles transversales al cauce principal. El periodo de registro de datos horarios fue entre febrero y noviembre de 2011.

Tres de los cuatro instrumentos instalados en el transecto localizado en la sección poniente fueron robados en dos ocasiones, por lo que solo se cuenta con registros parciales e incompletos. Este transecto fue excluido del análisis.

En segundo lugar, para evaluar en qué medida las zonas ribereñas y los parques asociados tienen un efecto enfriador se analizaron las diferencias de temperatura entre los puntos del transecto en función de su distancia al cauce principal, y las diferencias entre las temperaturas de la zona ribereña y de la matriz urbana representada por una estación meteorológica oficial. Para esto último se seleccionaron los días más cálidos del periodo registrado donde el rol enfriador se debiese observar mejor.

\section{Mitigación de inundaciones}

Las áreas de inundación fueron mapeadas usando la información sobre riesgo de inundación existente en instrumentos de planificación territorial a nivel metropolitano (Plan Regulador Metropolitano de Santiago) y comparadas con la zona ribereña bajo análisis. Posteriormente se analizó la medida en que las áreas ribereñas actúan como zonas de amortiguación protegiendo a la población e infraestructura de eventuales desbordes. Para esto se usó como indicador la ocupación de estas franjas ribereñas por parte de la población en términos de usos de suelo y cantidad de personas.

\section{Rutas para transporte no motorizado (bicicleta)}

En la primera parte se analizó en términos estructurales la infraestructura vial existente en las zonas ribereñas y en qué medida esta brinda soporte físico para viajes en bicicleta. Para lo anterior se recolectó, depuró y sistematizó información vectorial proveniente del Ministerio de Obras Públicas y del Gobierno Regional.

En la segunda parte, con el objetivo de conocer aspectos referidos a la frecuencia de uso de los parques ribereños como ruta de transporte y al perfil de los usuarios, se seleccionó un segmento del corredor ribereño para la aplicación de 753 encuestas. El área seleccionada corresponde al continuo definido por los parques Balmaceda y Uruguay que se despliegan desde el centro de la ciudad hacia el oriente a lo largo de 3,5 kilómetros aproximadamente (Figura $\mathrm{N}^{\circ} 1$ ).

\section{Servicios ecosistémicos relevantes en Santiago}

De Ios 15 SEs que pueden brindar las zonas ribereñas discutidos con el panel de expertos y actores locales, siete fueron considerados como los más importantes y necesarios en Santiago: 
- Corredor de viento

-Efecto enfriador

- Reducción de amenaza por inundación

- Recreación

De acuerdo a la clasificación del MEA (2005), de los siete SEs tres corresponden a servicios de regulación, dos a provisión y dos a culturales. Los actores y expertos valoran SEs diversos y diferentes a los clásicos de recreación y estéticos (culturales).

En los SEs de regulación se incluye el rol del río Mapocho como corredor de viento y su efecto enfriador sobre las temperaturas del aire. Ambos SEs están asociados a regulación climática, que corresponde a un tema importante para el panel consultado debido a la contribución potencial del río y sus zonas ribereñas a (1) la reducción de temperaturas cálidas extremas y el disconfort térmico experimentado en el verano, y (2) mejorar la circulación de viento en la cuenca, contribuyendo a evitar episodios críticos de contaminación atmosféricos que afectan a Santiago durante el otoño e invierno. El tercer SE de regulación considerado importante fue el rol que pueden cumplir las zonas ribereñas para evitar daños importantes producto de inundaciones por desbordes del río.
- Hábitat de plantas nativas

- Hábitat de fauna nativa

- Ruta para transporte no motorizado

Los SEs de provisión considerados como relevantes son los de hábitat para flora y fauna nativa. Los expertos y actores son conscientes de la importancia de que en Santiago exista flora y fauna nativa adaptada y representativa de las condiciones geográficas locales, y que su existencia puede ayudar a disminuir los efectos negativos de la urbanización sobre los ecosistemas.

Finalmente, las oportunidades ofrecidas por las zonas ribereñas del río Mapocho para la realización de actividades recreativas y para ser usadas como rutas de transporte no motorizado pueden ser clasificadas como SEs culturales. Este tipo de SE fue relevantes para los consultados debido a la falta de espacios verdes públicos y ciclovías en Santiago, especialmente en la sección occidental del río, y a la demanda creciente por estos espacios.

De los siete servicios ecosistémicos inicialmente seleccionados como relevantes, tres de ellos están asociados directamente a medidas de mitigación y adaptación al cambio climático según presenta el Cuadro $\mathrm{N}^{\circ} 4$.

Cuadro $\mathrm{N}^{\circ} 4$

Servicios ecosistémicos asociados al combate del cambio climático

\begin{tabular}{|l|l|}
\hline \multicolumn{1}{|c|}{ Servicio Ecosistémico } & \multicolumn{1}{c|}{ Ámbito } \\
\hline Corredor de viento & Adaptación \\
Reducción de amenaza por inundación & Adaptación \\
Efecto enfriador & Adaptación - Mitigación \\
Ruta para transporte no motorizado & Mitigación \\
\hline
\end{tabular}

Fuente: Elaboración propia. 
La Figura $\mathrm{N}^{\circ} 2$ muestra la importancia asignada a cada SE por los actores consultados, pudiéndose ordenar de la siguiente forma en base a la cantidad de veces que fueron seleccionados como el primer, segundo y tercer SE más importante: (1) Recreación,
(2) Ruta para transporte no motorizado, (3) Corredor de viento, (4) Reducción de amenaza por inundación, (5) Efecto enfriador, (6) Hábitat de flora nativa y (7) Hábitat de fauna nativa.

Figura $\mathrm{N}^{\circ} 2$

Importancia de los servicios ecosistémicos de acuerdo a la preferencia de los actores locales

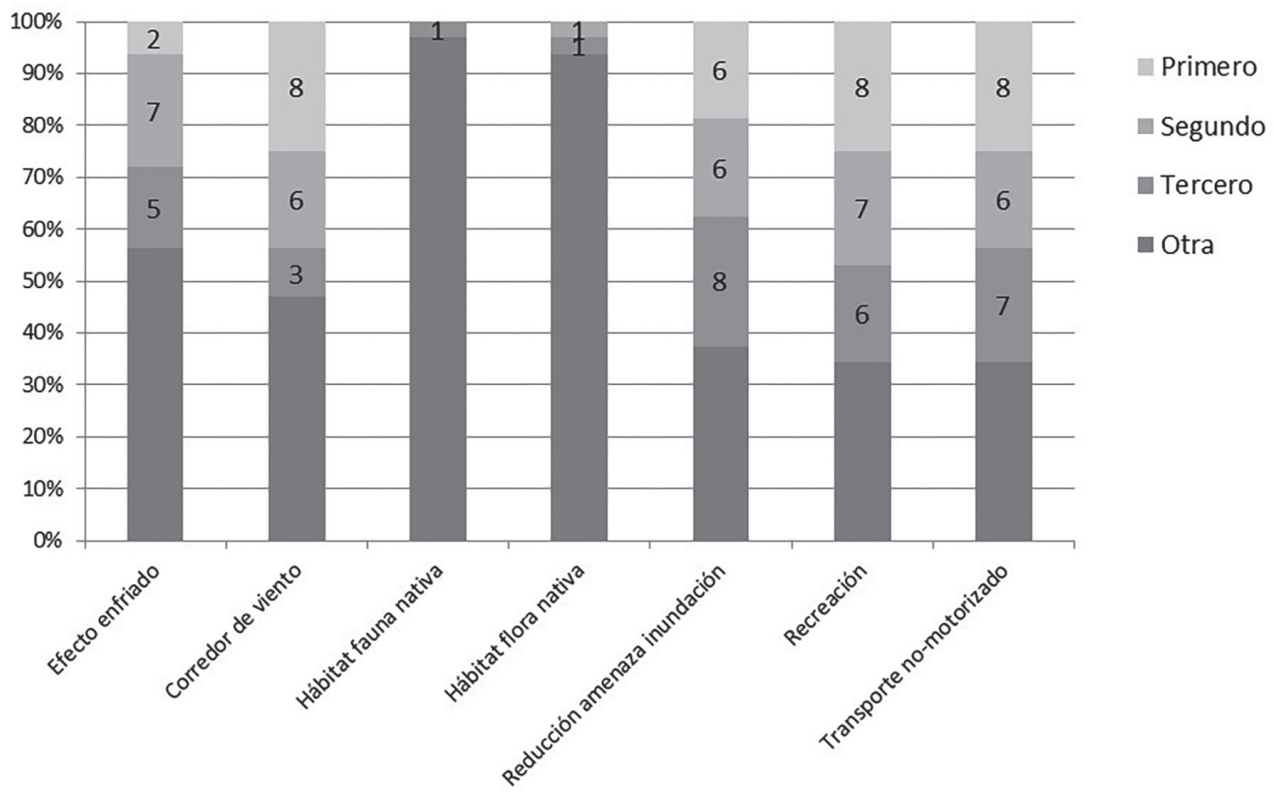

Fuente: Elaboración propia.

21 actores consideran que las oportunidades de recreación y la oferta de rutas para transporte no motorizado están dentro de los tres SEs más importantes, con una leve ventaja de recreación, por lo cual son clasificados como el primero y segundo más importantes respectivamente. Ambos son SEs culturales. EI tercer SE más relevante y necesario en Santiago corresponde al posible rol del río Mapocho como corredor de viento.

En síntesis, para los actores locales consultados los SEs asociados a la mitigación y adaptación al cambio climático resultan ser de los más importantes que puede proveer el río Mapocho y sus riberas, ya que por una parte, estos corresponden a cuatro de los siete SEs seleccionados inicialmente como re- levantes, y por la otra, estos cuatro SEs se sitúan dentro de los primeros cinco lugares del ranking final. Únicamente el rol de las áreas verdes como espacios de recreación aparece dentro de los cinco SEs más importantes y no tiene relación directa con medidas para enfrentar el cambio climático.

\section{Provisión de servicios ecosistémicos}

La Figura $\mathrm{N}^{\circ} 3$ muestra los resultados de los transectos móviles efectuados en noviembre de 2011 y los patrones termales exhibidos por las diferentes secciones transversales a lo largo del corredor ribereño. 
Figura $\mathrm{N}^{\circ} 3$

Transectos móviles de temperatura del aire, representados en función de la diferencia de en grados Celsius respecto al punto central localizado sobre el río (P3). Tarde del 11/01/2011

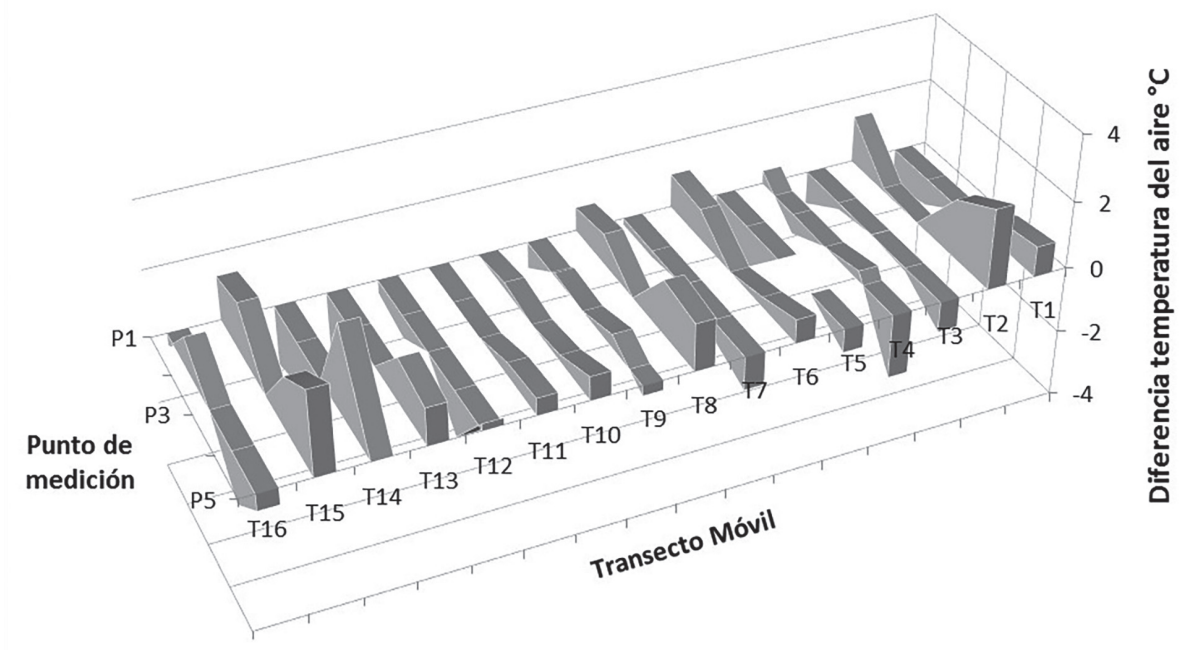

Fuente: Elaboración propia.

En general, se observa que incluso durante la tarde, periodo donde se espera que el rol enfriador sea máximo, existe una alta complejidad en las variaciones de la temperatura del aire en relación a la distancia al río (P3), lo que dificulta el reconocimiento claro de patrones espaciales

Solamente los transectos 2, 6, 8 y 15 muestran el aumento característico en la temperatura del aire desde el río hacia las áreas circundantes que es posible esperar. El transecto 15 es el caso más notable y representativo del rol enfriador del río y corredor ribereño, ya que los puntos localizados a 100 m (P2 y P4) y a 200 m (P1 y P5) del cauce son un promedio de $1,65^{\circ} \mathrm{C}$ y $1,9^{\circ} \mathrm{C}$, respectivamente, más cálidos que el punto $\mathrm{P} 3$ localizado sobre el cauce (Figura $N^{\circ} 3$ ).

En contraste, las temperaturas registradas sobre el cauce en los transectos 3, 5 y 7 son más cálidas que aquellas medidas a 100 y 200 m de distancia desde el curso de agua. Es decir, las temperaturas del aire son más cálidas cerca del río.

Existen patrones espaciales y termales altamente complejos, por ejemplo, en transectos vecinos la zona del cauce llega a estar $3^{\circ} \mathrm{C}$ más fría en uno y $3^{\circ} \mathrm{C}$ más cálida en el otro con respecto a la matriz urbana. Esto parecería indicar que durante el día factores locales como el uso y la cobertura de suelo serían más importantes que factores como la topografía, elevación o distancia al cauce.

Al utilizar la información de los registradores HOBO es posible observar que en términos globales la temperatura del aire medida en la zona ribereña del río Mapocho no difiere de manera significativa de las temperaturas registradas en la matriz urbana durante el verano $(p<0.05)$, que es precisamente la estación del año donde se espera la máxima diferencia entre un curso de agua, incluyendo su corredor ribereño, y la matriz urbana más densamente construida.

La Figura $N^{\circ} 4$ muestra la temperatura del aire para los dos días más cálidos registrados durante el verano del año 2011, en uno de los tres transectos equipados en el corredor ribereño y también en la estación oficial más cercana. Aunque los puntos 4 y 5 son $0.5^{\circ} \mathrm{C}$ más fríos que la estación Independencia, esta diferencia no es estadísticamente significativa $(p<0.05)$. En otras palabras, el corredor ribereño no está proveyendo un efecto enfriador a la ciudad. 
Figura $\mathrm{N}^{\circ} 4$

Temperatura del aire para los dos días más cálidos registrados en verano de 2011
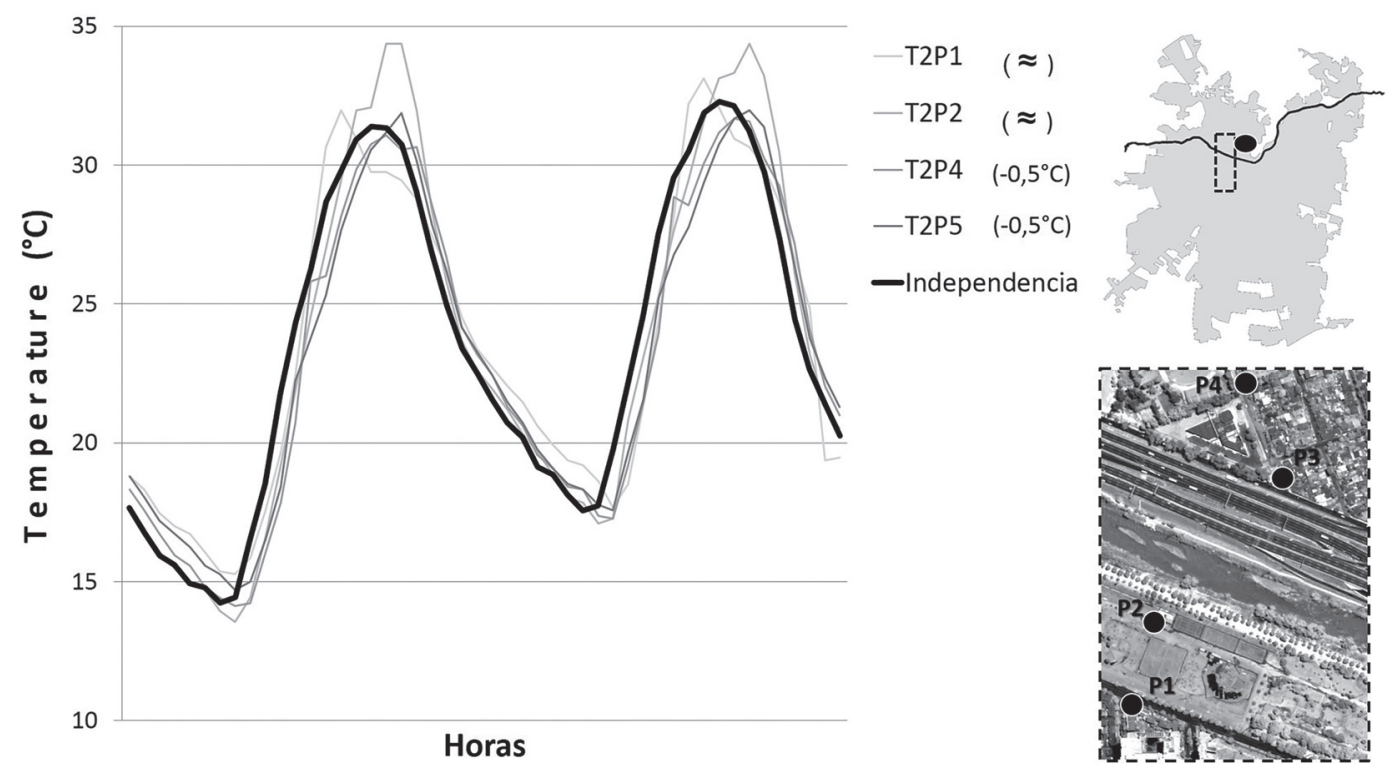

$\mathrm{T} 2=$ transecto $2, \mathrm{Pn}^{\circ}=$ punto de medición Fuente: Elaboración propia.

\section{Mitigación de inundaciones}

El corredor ribereño del río Mapocho no ha conseguido escapar de los procesos de urbanización, ya que actualmente el $36 \%$ de su superficie es ocupado por sectores residenciales (el $22 \%$ son del tipo denso) y un $13 \%$ por zonas industriales, comerciales, institucionales y autopistas urbanas. Lo anterior en conjunto representa el $49 \%$ de la zona ribereña.

Sin embargo, aún siguen existiendo importantes áreas ocupadas por formaciones vegetales seminaturales $(10,4 \%)$, áreas verdes urbanas $(14,8 \%)$ y de suelo desnudo $(20,9 \%)$, lo que significa que el $46,1 \%$ de la superficie del corredor ribereño ha logrado evitar la instalación de usos con mayores densidades poblacionales y de infraestructura.

Sin embargo, los sectores residenciales antes mencionados y especialmente los com- plejos habitacionales de alta densidad, sobre todo en la sección poniente, han sido construidos preferentemente en el área de inundación del río Mapocho. Lo anterior ha tenido como resultado que el $70 \%$ de la población que vive en la zona ribereña del río Mapocho (alrededor de 40.000 personas) es afectada por inundaciones recurrentemente (cada dos años), y si se consideran episodios de inundación menos recurrentes (mayores periodos de retorno) el porcentaje de personas afectadas aumenta de manera importante.

En cuanto a la infraestructura urbana expuesta a inundaciones en esta zona, y como se detalla en el siguiente apartado de este artículo, existen importantes autopistas urbanas que corren adyacentes al río por ambas riberas y que están en serio peligro de ser afectadas por eventuales desbordes.

En síntesis, en términos globales el corredor ribereño no actúa como un buffer de protección para la población e infraestructura 
urbana ante inundaciones en la mayor parte de su recorrido urbano.

\section{Rutas para transporte no motorizado}

La infraestructura de transporte en la zona ribereña del río Mapocho está altamente dominada por calles (incluyendo pequeñas calles y grandes avenidas) y autopistas urbanas, que representan un $72,2 \%$ y $25,5 \%$ respectivamente de los kilómetros lineales construidos. Estas dos categorías representan de manera conjunta el $97,7 \%$ de la red vial en la zona ribereña.

Actualmente, las ciclovías representan solo el 2,3\% de la infraestructura vial, es decir, la red de caminos existente está claramente orientada al transporte motorizado y especialmente a los automóviles.

Figura $N^{\circ} 5$

Estructura de la red vial

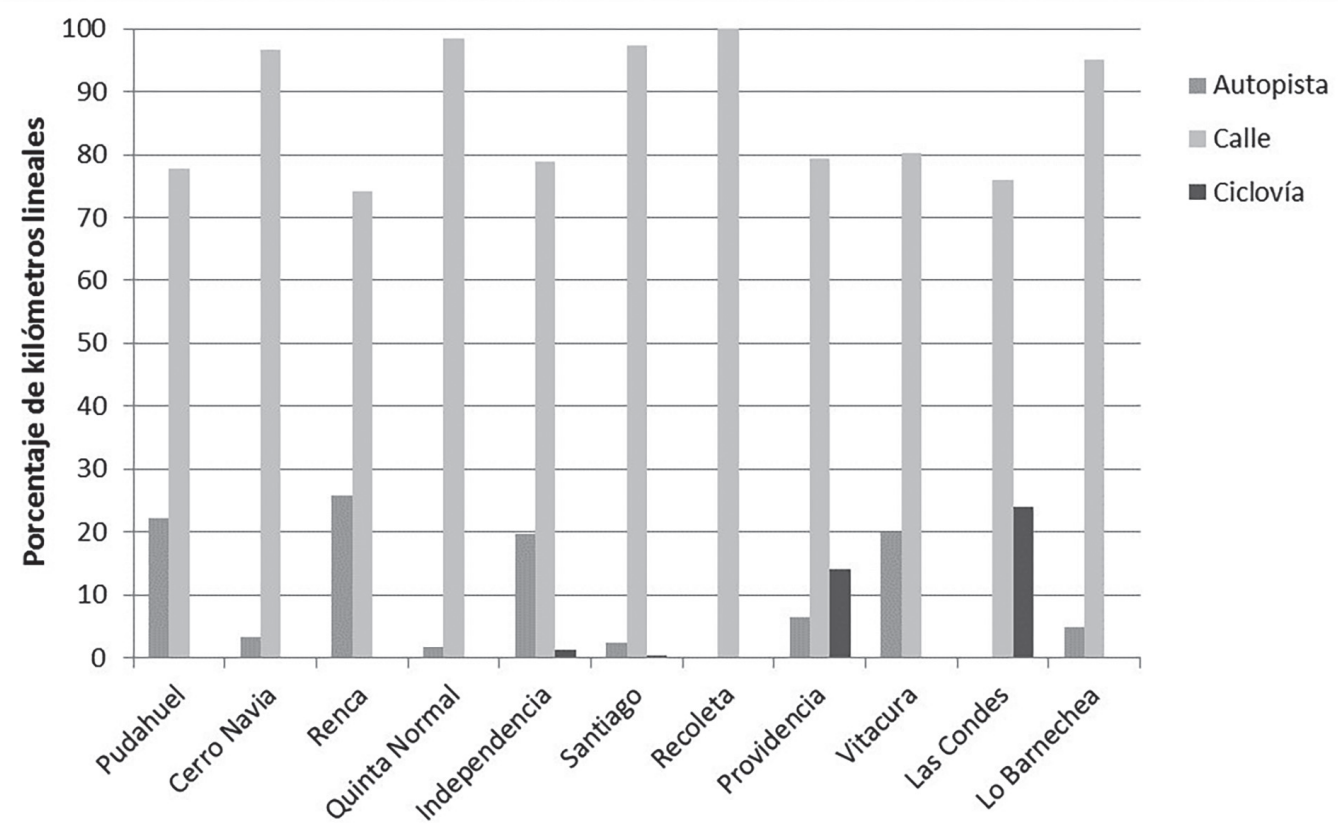

Comunas

Fuente: Elaboración propia.

La variación longitudinal este-oeste de la infraestructura vial se aprecia en la Figura $N^{\circ} 4$. Las calles son el tipo predominante de vía, representando más del $50 \%$ de la red de transporte en todas las municipalidades por las que atraviesa el río Mapocho en su tramo urbano. En la sección occidental de la zona ribereña la presencia de autopistas urbanas se vuelve altamente relevante, Ilegando a representar cerca del $46 \%$ de la red vial en Pudahuel y Renca.

Las ciclovías no son comunes en la zona ribereña y solamente en los municipios de Providencia y Las Condes están algo mejor representadas con más de un $10 \%$. En ambas comunas las ciclovías existentes en esta área se han implementado en los parques ribere- 
ños consolidados, lo cual ha representado una ventaja comparativa respecto a otras comunas.

El estudio en profundidad realizado a través de encuestas en los parques Balmaceda y Uruguay, entregó como resultado que su uso como ruta de transporte no motorizado (35\%) es casi tan importante como su uso como espacio de recreación. Estos parques lineales son altamente preferidos por las personas para movilizarse en bicicleta de un punto a otro de la ciudad, y constituyen parte importante de las rutas que recorren las personas entre su hogar y lugar de estudio o trabajo.

Aquellos usuarios que usan los parques para movilizarse a lo largo de él lo frecuentan más que aquellos que lo visitan con otros propósitos, por ejemplo, el $48 \%$ de los usua- rios se movilizan en bicicleta diariamente (Figura $\mathrm{N}^{\circ} 6$ ). En consecuencia, la mayor cantidad de personas que utiliza estos parques lo hace para realizar sus viajes cotidianos (o parte de ellos).

Adicionalmente, es importante destacar que las personas que abandonan la bicicleta para usar otro medio de transporte en la época de invierno, que podría ser catalogada como la más adversa para dicho fin, alcanzan solamente el $2 \%$.

En resumen, aunque la infraestructura vial está claramente orientada al transporte motorizado y no ofrece grandes oportunidades para el traslado en bicicleta, cuando existen las condiciones, como en el caso del corredor Balmaceda y Uruguay, las personas hacen un uso intensivo de estas oportunidades.

Figura $\mathrm{N}^{\circ} 6$

Frecuencia del uso del parque para transporte en bicicleta y otras actividades

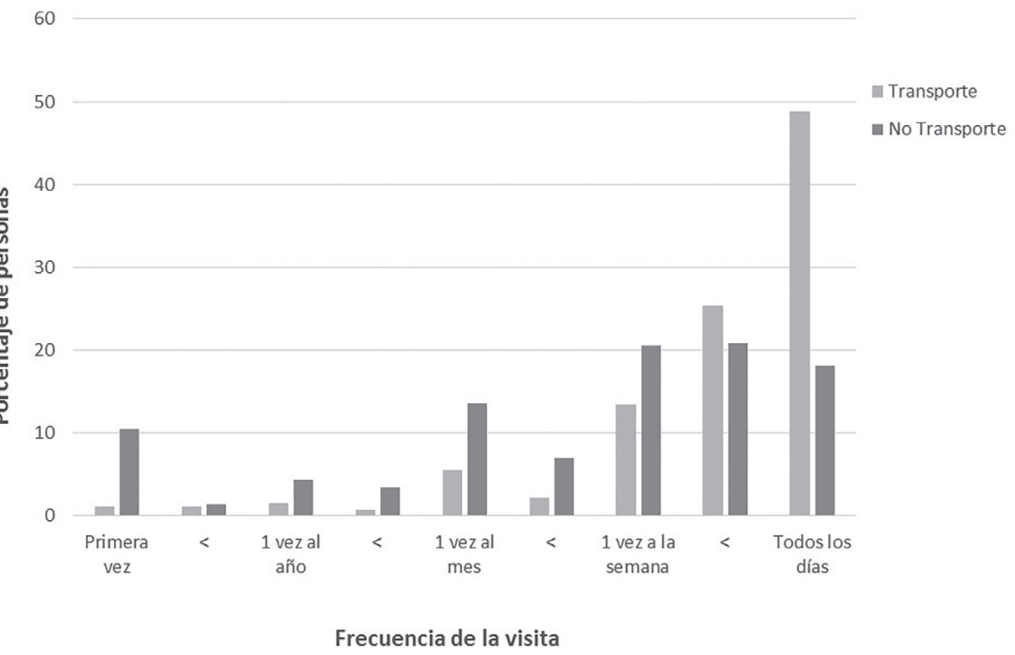

Fuente: Elaboración propia. 


\section{Discusión y conclusiones}

Este artículo contribuye en el campo de la infraestructura verde urbana principalmente de dos formas: (1) proponiendo un marco conceptual-analítico que oriente de manera concreta la evaluación, planificación y puesta en valor de los espacios verdes como estrategia para enfrentar el cambio climático en ambientes urbanos; y (2) aportando conocimiento específico respecto del rol del corredor ribereño del río Mapocho en Santiago (a modo de caso de estudio) para enfrentar el cambio climático por medio de la evaluación de tres servicios ecosistémicos.

Respecto a lo primero, la articulación analítica de los conceptos de infraestructura verde, servicios ecosistémicos y adaptación/ mitigación al cambio climático, permite esclarecer la forma en que los espacios verdes urbanos aportan a enfrentar el calentamiento global y los efectos negativos derivados de cambio climático. La infraestructura verde puede aportar tanto a la mitigación como a la adaptación al cambio climático, lo que incluso puede ocurrir de manera simultánea debido al carácter multifuncional de los espacios verdes y ecosistemas urbanos. Por lo anterior, cualquier estrategia para enfrentar el cambio climático en las ciudades que centre sus esfuerzos en la conservación o desarrollo de infraestructura verde puede ser considerada altamente eficiente.

El marco conceptual-analítico desarroIlado avanza hacia la integración del conocimiento y desarrollo teórico sobre los SEs urbanos con el campo eminentemente práctico de la planificación de infraestructura verde, contribuyendo a disminuir la brecha identificada por Hansen \& Pauleit (2014) en este sentido.

Si bien es cierto la aplicación se realizó sobre un tipo particular de infraestructura verde en términos funcionales (corredor) a escala de ciudad (zona ribereña) (Benedict \& McMahon, 2006; EEA, 2011; Landscape Institute, 2009), la aproximación propuesta puede ser usada en otros tipos de infraestructura verde (nodos y núcleos) y a otras escalas (barrio y región). De esta misma forma, la aproximación metodológica puede ser adaptada y apli- cada a diferentes contextos urbanos, y para evaluar SEs diferentes a los seleccionados en este estudio.

El caso de Santiago demuestra cómo el marco analítico puede ser aplicado concretamente a través de la evaluación de los aportes reales de infraestructura verde existente para afrontar el cambio climático usando una aproximación basada en indicadores.

Los resultados indican que los actores y expertos locales identificaron la recreación, ruta de transporte no motorizado y corredor de viento como los tres SEs más relevantes en el caso del corredor ribereño del río Mapocho en Santiago. Estos fueron seguidos en importancia por mitigación de inundaciones y efecto enfriador.

Lo anterior involucra una mirada más compleja y amplia de parte de los actores locales que la tradicional enfocada en los beneficios estéticos y recreacionales de los espacios verdes urbanos, lo cual podría estar asociado a la creciente importancia de estos en el debate sobre calidad de vida y desarrollo sustentable (Bachellet, 2014; Opazo y Jaque, 18 de octubre de 2014). El reconocimiento de los múltiples aportes potenciales de un corredor verde ribereño asociado al río Mapocho para enfrentar el cambio climático, podría significar que un plan o proyecto para su desarrollo contaría con un mayor apoyo político y social.

Los aportes actuales del corredor ribereño del río Mapocho son principalmente respecto a la mitigación de emisiones de gases invernadero al servir como una importante ruta para desplazamiento en bicicleta dentro de la ciudad. Pese a que la infraestructura vial existente en la zona ribereña está importantemente orientada al transporte motorizado, siendo las ciclovías muy escasas, los parques consolidados como el Balmaceda y Uruguay son usados por las personas principalmente como rutas habituales (entre todos los días y varias veces a la semana) para transportarse entre su domicilio y lugar de estudio o trabajo.

En este sentido, existen varias iniciativas comunales y regionales para aumentar la extensión de las ciclovías en la ciudad y 
algunas de estas iniciativas están enfocadas especialmente en las zonas ribereñas, por ejemplo, el proyecto Mapocho $42 \mathrm{~K}$ plantea la construcción de una ciclovía en todo el tramo urbano del río Mapocho. Sin embargo, como las autopistas urbanas han sido construidas en la zona ribereña del río Mapocho e inmediatamente adyacentes al cauce, el espacio disponible para la construcción de ciclovías se reduce enormemente.

El rol del río y sus riberas como regulador térmico actualmente no parece ser significativo, y solo puede ser observado en ciertas secciones. La presencia de obras de canalización e infraestructura vial de gran magnitud en estas áreas podrían explicar por qué en algunos tramos la zona ribereña es más cálida que la zona construida en la matriz urbana vecina. Sin embargo, este SE puede ser incrementado introduciendo mejoras en el diseño y paisajismo de los espacios verdes.

Actualmente la zona ribereña del río Mapocho presenta una condición dual en el sentido que, por una parte, existe una importante cantidad de personas e infraestructura expuesta a inundaciones, y por otra, casi el $30 \%$ de la superficie del corredor ribereño corresponde a suelo desnudo que podría ser mantenido sin desarrollo y consolidado como área verde. De todas formas, su acción como buffer de protección de personas e infraestructura ante inundaciones ocasionadas por desbordes del río es mucho más difícil de mejorar, ya que esto implicaría en muchos casos reasentamiento de población y relocalización de importante infraestructura urbana.

Los resultados de la evaluación entregan antecedentes que permiten comprender los aportes actuales del corredor verde ribereño para enfrentar el cambio climático y de esta manera orientar posibles acciones para mejorar cuantitativa y cualitativamente dicho aporte. A nivel de ciudad, esto puede ser materializado mediante un plan para el desarrollo de un corredor verde ribereño en el río Mapocho, que incluya como uno de sus objetivos contribuir a la mitigación y adaptación al cambio climático.

La implementación de un corredor verde multifuncional en el río Mapocho puede ser visto como un importante paso para la conso- lidación de un sistema de infraestructura verde a nivel de ciudad en Santiago, que integre espacialmente los diferentes componentes de infraestructura verde existentes y proyectados.

\section{Referencias bibliográficas}

ALBERTI, M. Advances in Urban Ecology: Integrating Humans and Ecological Processes in Urban Ecosystems. Berlin: Springer, 2008.

APAN, A.; RAINE, S. \& PATERSON, M. Mapping and analysis of changes in the riparian landscape structure of the Lockyer Valley catchment, Queensland, Australia. Landscape and Urban Planning, 2002, Vol. 59, $\mathrm{N}^{\circ} 1$, p. 43-57.

BACHELET, M. Ciudad, vivienda y territorio. Programa de gobierno 2014-2018. 2014. Disponible en Internet: http://michellebachelet.cl/wp-content/uploads/2013/10/CiudadVivienda-y-Territorio-120-125.pdf

BENEDICT, M. \& MCMAHON, E. Green Infrastructure. Washington: Island Press, 2002.

BENEDICT, M. \& MCMAHON, E. Green Infrastructure: Linking Landscapes and Communities. Washington: Island Press, 2006.

BOLUND, P. \& HUNHAMMAR, S. Ecosystem services in urban areas. Ecological ECOnomics, 1999, Vol. 29, p. 293-301.

BOYD, J. \& BANZHAF, S. What are ecosystem services? The need for standardized environmental accounting units. Ecological Economics, 2007, Vol. 63, N² 2, p. 616-626.

CABESPACE. Is the grass greener...? Learning from international innovations in urban green space management. London: CABE Space, Bartlett School of Planning, University College London 2003.

CBO. Cities and Biodiversity Outlook, 2013. Disponible en Internet: http://cbobook.org

COSTANZA, R.; D'ARGE, R.; DE GROOT, R.; FARBERK, S.; GRASSO, M.; HANNON, B.; LIMBURG, K.; NAEEM, S.; O'NEILL, R.; 
PARUELO, J.; RASKIN, R.; SUTTONKK, P. \& VAN DEN BELT, M. The value of the world's ecosystem services and natural capital. Nature, 1997, Vol. 387, p. 253-260.

DEPARTAMENTO DE GEOFÍSICA DE LA UNIVERSIDAD DE CHILE (DGF). Estudio de la variabilidad climática en Chile para el Siglo XXI. Informe Final. Santiago de Chile: CONAMA, 2006.

DUNNETT, N.; SWANWICK, C. \& WOOLLEY, H. Improving urban parks, play áreas and green spaces. London: Office of the Deputy Prime Minister, 2002.

EUROPEAN ENVIRONMENT AGENCY (EEA). Green infrastructure and territorial COhesion - The concept of green infrastructure and its integration into policies using monitoring systems. Luxembourg: EEA, 2011.

EISENMAN, T. Frederick Law Olmsted, Green Infrastructure, and the Evolving City. Journal of Planning History, 2013, Vol. 12, N ${ }^{\circ}$ 4, p. 287-311.

FEENSTRA, J. Handbook on Methods for Climate Change Impact Assessment and Adaptation Strategies. Amsterdam: United Nations Environment Programme, and Vrije Universiteit te Amsterdam. Instituut voor Milieuvraagstukken, 1998.

FISHER, B.; TURNER, K. \& MORLING, P. Defining and Classifying Ecosystem Services for Decision Making. Ecological Economics, 2009, No3, p. 643-653.

GILL, S.; HANDLEY, J.; ENNOS, A.; PAULEIT, S.; THEURAY, N. \& LINDLEY, S. Characterising the Urban Environment of UK Cities and Towns: A Template for Landscape Planning. Landscape and Urban Planning, 2008, Vol. $87, \mathrm{~N}^{\circ} 3$, p. 210-222.

GILL, S.; HANDLEY, J.; ENNOS, A. \& PAULEIT, S. Adapting Cities for Climate Change: The Role of the Green Infrastructure. Built Environment, 2007, Vol. 33, № 1, p. 115-133.

GOBIERNO REGIONAL METROPOLITANO DE SANTIAGO; MINISTERIO DE MEDIO AMBIENTE NACIONAL \& SECRETARÍA
REGIONAL MINISTERIAL DE MEDIO AMBIENTE. Plan de Adaptación al cambio climático para la Región Metropolitana. Santiago de Chile: Proyecto Clima Adaptación Santiago, 2012.

GOODMAN, L. Snowball Sampling. The Annals of Mathematical Statistics. 1961. Vol $32, \mathrm{~N}^{\circ} 1$, p. 148-155.

GIRLING, C.; KELLETT, R.; ROCHEFORT, J. \& ROE, C. Green Neighborhoods. Eugene: Center for Housing Innovation, University of Oregon, 2000.

HAASE, D.; LARONDELLE, N.; ANDERSSON, E.; ARTMANN, M.; BORGSTRÖM, S.; BREUSTE, J.; GOMEZ-BAGGETHUN, E.; GREN, A.; HAMSTEAD, Z. \& HANSE, R. A Quantitative Review of Urban Ecosystem Service Assessments: Concepts, Models, and Implementation. Ambio, 2014, Vol. 43, $\mathrm{N}^{\circ} 4$, p. 413-433.

HAMIN, E. \& GURRAN, N. Urban Form and Climate Change: Balancing Adaptation and Mitigation in the US and Australia. Habitat International, 2009, Vol. 33, № 3, p. 238245.

HANSEN, R. \& PAULEIT, S. 2014. From multifunctionality to multiple ecosystem services? A Conceptual framework for multifunctionality in green infrastructure planning for urban areas. Ambio, 2014, Vol. 43, No 4, p. 516-529.

HELLMUND, P. \& SMITH, D. Designing Greenways: Sustainable Landscapes for Nature and People. Washington: Island Press, 2006.

HERNÁNDEZ-MORCILLO, M.; PLIENINGER, T. \& BIELING, C. An empirical review of cultural Ecosystem services indicators. Ecological Indicators, 2013, Vol. 29, p. 434-444.

INSTITUTO NACIONAL DE ESTADÍSTICAS. Indicadores Económicos, 2009. Disponible en Internet: http://www.ine.cl/canales/chile_estadistico/mercado_del_trabajo/ nene/series_referenciales.php.

INTERGOVERNMENTAL PANEL ON CLIMATE CHANGE (IPCC). Climate change 
2007: The Physical Science Basis. Contribution of Working Group I to the Fourth Assessment Report of the Intergovernmental Panel on Climate Change. Cambridge: ed. Solomon S, Cambridge University Press, 2007, p. 996101.

JACKSON, L. The relationship of urban design to human health and condition. Landscape and Urban Planning, 2003, Vol. 64, p. 191-200.

KANDZIORA, M.; BURKHARD, B. \& MÜLLER, F. Interactions of ecosystem properties, ecosystem integrity and ecosystem service indicators-A theoretical matrix exercise. Ecological Indicators, 2013, Vol. 28, p. 54-78.

KAZMIERCZAK, A. \& CARTER, J. Adaptation to Climate Change Using Green and Blue Infrastructure. A Database of Case Studies. GRaBS EU, 2010. Disponible en Internet: http://www.grabs-eu.org/casestudies.php, 2010.

KITHA, J. \& LYTH, A. Urban Wildscapes and Green Spaces in Mombasa and Their Potential Contribution to Climate Change Adaptation and Mitigation. Environment and Urbanization, 2011, Vol. 23, $\mathrm{N}^{\circ} 1$, p. 251 265

LANDSCAPE INSTITUTE. Green infrastructure: connected and multifunctional landscapes. Londres: Landscape Institute Position statement, 2009.

LAUF, S.; HAASE, D. \& KLEINSCHMIT, B. Linkages Between Ecosystem Services Provisioning, Urban Growth and shrinkage-A Modeling Approach Assessing Ecosystem Service Trade-offs. Ecological Indicators, 2014, (en prensa).

LUNDY, L. \& WADE, R. Integrating Sciences to Sustain Urban Ecosystem Services. Progress in Physical Geography, 2011, Vol. 35, No 5, p. 653-669.

MAEKAWA, M. \& NAKAGOSHI, N. Riparian landscape changes over a period of 46 years, on the Azusa River in Central Japan. Landscape and Urban Planning, 1997, Vol. $37, N^{\circ} 1-2$, p. 37-43.
MCMAHON, E.T., \& BENEDICT, M.A. Green infrastructure. Planning Commissioners Journal, 2000, No 37, p. 4-7.

MILLENIUM ECOSYSTEM ASSESSMENT (MEA). Ecosystem and Human Well-being: Current State and Trends. Washington: Island Press, 2005.

MOLINA, M. Efectos de los tipos de urbanización asociados al crecimiento urbano del área Metropolitana del Gran Santiago sobre la generación y comportamiento de micro islas de calor. Santiago de Chile: Memoria para optar al Título Profesional de Geógrafo, Facultad de Arquitectura y Urbanismo, Universidad de Chile, 2007.

NIEMELÄ, J.; SAARELA, S.; SÖDERMAN, T.; KOPPEROINEN, L.; YLI-PELKONEN, V.; VÄRE, S. \& KOTZE, D. Using the ecosystem services approach for better planning and conservation of urban green spaces: a Finland case study. Biodiversity and Conservation, 2010, Vol. 19, No 11, p. 3225-3243.

OPAZO, T. y JAQUE, J. La pelea por el área verde. Diario La Tercera (18 de octubre 2014). Disponible en Internet: http://www.latercera.com/noticia/tendencias/2014/10/659600763-9-la-pelea-por-el-area-verde.shtml

PICKETT, S.; CADENASSO, M.; GROVE, J.; BOONE, C.; GROFFMAN, P.; IRWIN, E.; KAUSHAL, S.; MARSHALL, V.; MCGRATH, B. \& NILON, C. Urban Ecological Systems: Scientific Foundations and a Decade of Progress. Journal of Environmental Management, 2011, Vol. 92, $N^{\circ} 3$, p. 331-362.

RESILIENCE ALLIANCE. Urban Resilience. CANBERRA: Research Prospectus, 2007.

ROMERO, H. Geografía de los climas de Chile: Tomo XI colección de Geografía de Chile. Santiago de Chile: Editorial Instituto Geográfico Militar (IGM), 1985.

ROMERO, H. \& VÁSQUEZ, A. La Comodificación de los Territorios Urbanizables y la Degradación Ambiental en Santiago de Chile. En: CAPEL, H. \& HIDALGO, R. Construyendo la Ciudad del Siglo XXI. Retos y Perspectivas urbanas en España y Chile. Santiago de Chile: 
Serie GEOlibros, Instituto de Geografía, Pontiticia Universidad Católica de Chile, 2006, p. 263-277.

ROMERO, H.; VÁSQUEZ, A.; FUENTES, C.; SALGADO, M.; SCHMIDT, A. \& BANZHAF, E. Assessing urban environmental segregation (UES). The case of Santiago de Chile. Ecological Indicators, 2012, № 23, p. 76-87.

SANTIAGO-RAMOS, J. La naturaleza en la ciudad: perspectivas teóricas y metodológicas para el estudio de la funcionalidad ambiental del espacio libre. Sevilla: Junta de Andalucía, Consejería de Obras Públicas y Transportes, 2008.

SCHREIER, H.; HALL, K.; BROWN S.; LAVKULICH, \& ZANDBERGEN, P. Integrated Watershed Management. Vancouver: CDROM. Institute for Resources and Environment, University of British Columbia, 2004.

SMANIOTTO, C.; SUKLJE, I. \& MATHEY, J. Green spaces-a key resources for urban sustainability. The Green Key approach for developing green spaces. Urbani izziv, 2008, Vol. 19, № 2, p. 199-211.

SUKOPP, H. \& WERNER, P. Naturaleza en las ciudades: Desarrollo de flora y fauna en áreas urbanas. Madrid: Ministerio de Obras Públicas y Transportes, 1991.

THOMPSON, W. Urban Open Space in the 21 st Century. Landscape and Urban Planning, 2002, Vol. $60, \mathrm{~N}^{\circ} 2$, p. 59-72.

TZOULAS, K.; KORPELA, K.; VENN, S.; YLI-PELKONEN, V.; KAZMIERCZAK, A.; NIEMELA, J. \& JAMES, P. Promoting Ecosystem and Human Health in Urban Areas Using
Green Infrastructure: A Literature Review. Landscape and Urban Planning, 2007, Vol. 81, No 3, p. 167-178.

VÁSQUEZ, A.; SANDOVAL, G. \& MÉNDEZ, M. Diagnóstico geográficoambiental de las zonas riparianas urbanas en Santiago de Chile: explorando su potencial como Greenways. El caso del río Mapocho, el Zanjón de la Aguada y la Quebrada Nido de Águila. Anales de la Sociedad Chilena de Ciencias Geográficas, 2010, p.78-85.

VÁSQUEZ, A. \& ROMERO, H. El libremercado de las áreas urbanas y la falta de justicia ambiental en la disponibilidad de áreas verdes en Santiago de Chile. En: Actas del IX Coloquio Internacional de Geocrítica. Los Problemas del Mundo Actual. Soluciones y Alternativas desde la Geografía y las Ciencias Sociales, 2007. Disponible en Internet: http://www.ub.es/geocrit/9porto/hromero.htm

WALMSLEY, A. Greenways: multiplying and diversifying in the 21 st century. Landscape and Urban Planning, 2006, Vol. 76, p. 252-290.

WALLACE, K. Classification of Ecosystem Services: Problems and Solutions. Biological Conservation, 2007, Vol. 139, No 3-4, p. 235-246.

WILLIAMSON, K. Growing with green infrastructure. Doylestown: Heritage Conservancy, 2003. 